\title{
Brand Joint Research Based on Geographical Indication Agricultural Products Network
}

\author{
Chen Daifen ${ }^{1, *}$,Zou Fang ${ }^{1}$, Zhang $\mathrm{Li}^{1}$, Fan $\mathrm{Min}^{1}$, and Yi Jiao ${ }^{1}$ \\ ${ }^{1}$ Sichuan Agricultural University, School of Business, China
}

\begin{abstract}
This paper studies the network structure of geographical indication agricultural products in the field of e-commerce in Sichuan Province, and discusses the joint mechanism of geographical indication brands based on network structure. Taking the geographical indication products as the node, the consumer's purchase behavior is the connection relationship, and the network structure of the geographical indication products is analyzed from the perspective of consumer behavior, and then the regional brand creation is based on this. This paper constructed a product_ product network__brand alliance_—regional brand geographical indication agricultural product regional brand creation path. The paper focuses on the resource dependent brand joint behavior based on individual interests, and the joint behavior of geographically dependent brands based on the perspective of regional interests. When the brand joint starting point is based on individual interests, it will tend to choose resource-based agricultural product brands that have strong commodity-related strength and can bring the greatest consumer transformation to themselves; when the brand joint starting point is to promote the regional-based regional economy, it will tend to start from the cluster-based brand alliance, emphasizing the development of a good geographical indication agricultural product brand to promote the development of a geographically-improved GI brand.
\end{abstract}

\section{Introduction}

As a special regional brand, geographical indication can bring economic protection to products, but it cannot be directly transformed into a successful brand to enhance its economic benefits. Especially in the field of ecommerce, the development of geographical indication industry still faces many problems, including low brand, lack of brand connotation, limited space for brand value growth, low visibility of agricultural GI brand online, lack of online sales channels, and slow growth of agricultural brands.

The development of e-commerce makes the GI product brand as a typical regional brand not only needs to carry out offline brand building, but more importantly, the construction of "Internet+ brand". The connotation of geographical indications indicates its innate cultural and quality information, and promotes the brand development of geographical indication protection products to achieve higher product premiums and promote the development of regional economy. This paper builds its product network based on the online sales of geographical indication agricultural products. Through the self-centered network of agricultural products and the overall network analysis, this paper proposes a brand association method (resource dependent and regional dependent type) of geographical indication agricultural products based on different interest starting points, and then creates different aagricultural product regional brand building path.

\section{Literature review}

\subsection{Social network}

Social network theory regards society as a network of connected organizations and individuals, and analyzes the influence of the network structure and content of actors on their behavior. Capaldo $(2007)^{[1]}$ proposes that social networks include, in addition to the flow of resources between enterprises, Inter-enterprise communication, cooperation and other forms of relationship. Ma Shuzhong (2016) based on the agricultural product import and export data of different countries from 1996 to 2013, discussed the influence of network centrality, network connection strength, network heterogeneity on the position of value chain division of labor of a country with the trading country as the node. Shao Jingbo (2017) based on the theory of social networks, extending the influence of brands on the driving factors of brand equity of parent brands.

The application of social networks in the field of brand marketing has also received extensive attention from scholars. David interprets the brand strategy from a new perspective and proposes the concept of "brand group" from the perspective of brand system. The brand network was originally proposed by Liu Qiuhong (2005) ${ }^{[2]}$. She defined the brand network as a network structure formed through the complex relationship between brands.

"Corresponding author: Zou Fang@94608053@qq.com.org 
The brand network mentioned in this study, namely the geographical indication agricultural product network, is a networked collection of geographical indication agricultural products that are connected by consumers' purchasing behavior. Huang Huang Xizhong and Yang Jianmei (2006) emphasized that there are similar competitions and symbiosis between different brands belonging to an industrial cluster. It is believed that different brands divide and occupy the industrial value chain resources through market position.

From the perspective of ecological network, the research of brand has laid a theoretical foundation for the application of social network theory in brand research. However, scholars' research on brand ecological network mostly focuses on concepts and connotations, and lacks in-depth research on the relationship between brands. Researching brands through social network methods can effectively explore the complex and unregulated relationships between brands and discover new mechanisms for brand association. The social network of this paper is constructed through two types of behavioral entities: products and consumers, and expands the previous research on social network construction with a single subject. The analysis of the structural characteristics of the product network based on the consumer's independent purchasing behavior is helpful to objectively analyse the utilization of the geographical indication agricultural products to the e-commerce channel, and at the same time help to explore the ecommerce regional brand development path of the geographical indication products.

\subsection{Brand joint research}

\subsubsection{Geographical Indication Regional Brand Growth Research}

Geographical indication products depend on a certain production location. Many researchers have explored regional brand building of geographical indication products from the perspective of industrial clusters and ecological chains. Xiu Wenyan (2010) through the study of geographical indications believes that the development of agricultural industry can be promoted through the form of brand linkage, and the promotion of agricultural industrialization by agricultural leading enterprises and foreign investment is pointed out. Guo Hongsheng and Zhou Xin (2007) ${ }^{[3]}$ defined the concept of eco-brand relationship based on geographical indication agricultural products, emphasizing the coordination relationship between brand and brand, brand and external subject, which contributes to the construction and development of GI brand.

Xie Min (2017) Geographical indications will affect consumers' attitudes towards the performance value of products, brand display, brand culture, and brand communication. Xu Wenping et al. (2011) pointed out the new path of GI brand development and promoted the branding of GI products through e-commerce platform. He Yan, Song Zhou, Yang Haifen (2006) for the lack of famous brand agricultural products in Chengdu plain and low brand awareness, proposed to adopt the "big brand" strategy, integrate local agricultural products, actively promote, increase publicity, and adopt trademark strategy, to increase the brand awareness of agricultural products.

The research on the method of regional brand building of geographical indication agricultural products mainly includes the following three aspects: (1) Establishing regional brands of geographical indication agricultural products through measures such as industrial clusters, strategic alliances and ecological chain clusters. (2) Equating the registration of geographical indications with brand building behavior. (3) Create regional brands through the brand image of GI products. In view of the shortcomings of the above research methods, this paper starts from the geographical indication products, through the network sub-group composed of consumers' selfpurchasing behaviors, and uses the brand to jointly build regional brands in the field of e-commerce. It not only extends the value enhancement space of the geographical indication brand, but also solves the limitation that the establishment of regional brands through clusters and the like needs to ensure that the enterprise/product brand is concentrated in a certain geographical area.

\subsubsection{Brand association}

The main focus of scholars on brand association research is the following: the motivation of brand association, joint risk and joint advantages. Fan Xiucheng and Zhang Yuyu discussed the advantages of brand association in terms of competitiveness, resources, brand awareness and cost. Ning Changhui (2006) believes that successful branding needs to consider two factors, including the matching of products and brands. The risk of brand coexistence is mainly the uncoordinated image, personality and concept of the partners. Lu Juan and Bian Yajing (2009) found that the perceived matching between brands will affect consumers' willingness to buy co-brands. Cao Lin (2012) ${ }^{[4]}$ constructed a coupling model of brand association from the perspective of brand credit and category fit. Liang Wei (2012) ${ }^{[5]}$ believes that there are two types of brand associations in the brand: brand association based on industrial value chain (horizontal joint, vertical joint),market-oriented brand association (depending on expanded brand association, mutual aid enhanced type brand alliance).

From the existing research, scholars have studied the factors affecting brand association from the perception of consumers before the joint brand, and believe that the individual brand matching degree before the joint, brand credit, individual attitudes of consumers will affect the joint brand utility. However, the research on brand joint mechanism from the perspective of social network is still relatively lacking, and the promotion mechanism of brand association to regional brands needs further discussion. Starting from the network structure of geographical indication agricultural products, this paper explores the joint mechanism of geographical indication brands in the e-commerce field, and provides new ideas for regional brand building of agricultural products. 


\section{Different brand joint forms under the geographical indications agricultural products network}

\subsection{Geographical indication agricultural product network}

This study builds a geographical indication agricultural product network based on the same purchase behavior. The network takes the commodity as the node, the same purchase behavior as the edge, and the appearance frequency as the weight. For example, consumer A purchases $\mathrm{a}, \mathrm{b}$, and e products in turn, and consumer B sequentially purchases $\mathrm{c}$, a, and $\mathrm{d}$ products, and consumer $\mathrm{C}$ sequentially purchases $\mathrm{e}, \mathrm{c}$, and a products, and consumer D sequentially purchases a, c, and $\mathrm{b}$, the network contains five nodes, seven edges, wherein the goods a and c are a two-way relationship, the weight of the side of $\mathrm{a}->\mathrm{c}$ is 1 , and the weight of the side of $\mathrm{c}->\mathrm{a}$ is 2 ,such as Figure 1 shows.

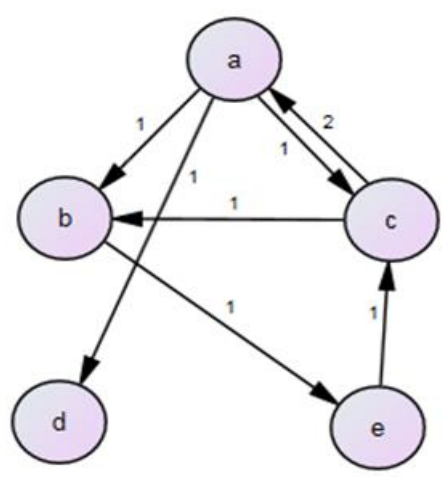

Fig. 1. Geographical indication agricultural product network.

\subsection{Resource-dependent brand association based on product network}

Reciprocity mainly refers to the degree of two-way relationship, indicating the degree of dependence between individuals (nodes) in the network ${ }^{[6]}$.In a directed network, there are three forms of connectivity between the subject and the subject, which are interconnected, unidirectional, and unconnected ${ }^{[7]}$.If two geographical indication products cannot be connected to each other through consumers, there is no flow of consumer resources between them, there is no output and input of consumer resources; one-way resource output exists between one-way connection reaction nodes, the other node does not have feedback on resources. That is, one GI product will input consumer resources to another GI product, and another GI product will not provide feedback; reciprocity in the product network is reflected in the flow of consumer resources is two-way, the node side to another One party has input for consumer resources. Some researchers pointed out that reciprocal connectivity indicates that the two nodes are more deeply involved in resource dependence and resource sharing ${ }^{[8]}$,so building a co-brand through reciprocal connected products will be more stable and stable.
Network reciprocal connections are often seen as "strong-strong" connections between nodes. In a reciprocal relationship, both parties can provide consumer resources to each other to form dependencies or controls. Therefore, both parties are in a favourable position in the brand joint strategic relationship. This paper evaluates the level of reciprocity between network nodes by measuring the degree of consumer conversion between the two nodes.

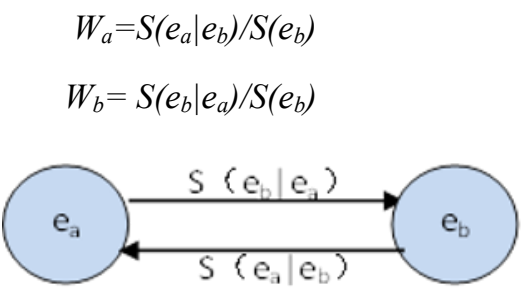

Fig.2. Geographical indication agricultural product network.

Where $\mathrm{S}\left(\mathrm{e}_{\mathrm{a}}\right)$ is the number of consumers who purchase product $e_{a}, S\left(e_{b}\right)$ is the number of consumers who purchase product $\mathrm{e}_{b}$, and $\mathrm{S}\left(\mathrm{e}_{\mathrm{a}} \mid \mathrm{e}_{\mathrm{b}}\right)$ is the number of consumers who purchase product ea after purchasing product $\mathrm{e}_{\mathrm{b}}, \mathrm{S}\left(\mathrm{e}_{\mathrm{b}} \mid \mathrm{e}_{\mathrm{a}}\right)$ The number of consumers who purchased the product $\mathrm{e}_{\mathrm{b}}$ after purchasing the product ea. $\mathrm{W}_{\mathrm{a}}$ is the degree of dependence of product $\mathrm{e}_{\mathrm{a}}$ on product $\mathrm{e}_{b}$, and $\mathrm{W}_{\mathrm{b}}$ is the degree of dependence of product $\mathrm{e}_{b}$ on product ea. When $\mathrm{W}_{\mathrm{a}}>\mathrm{W}_{\mathrm{b}}$, the brand association between product $e_{a}$ and product $e_{b}$ is a resourcedependent brand association, which includes two relationships, namely, the resource dependence of product $\mathrm{e}_{\mathrm{a}}$ on product $\mathrm{e}_{\mathrm{b}}$, and the relationship control relationship of product $\mathrm{e}_{\mathrm{b}}$ to product ea. When $\mathrm{W}_{\mathrm{a}} \approx \mathrm{W}_{\mathrm{b}}$, it indicates that the product $e_{a}$ and the product $e_{b}$ are interdependent, and the brand association between the product $\mathrm{e}_{\mathrm{a}}$ and the product $\mathrm{e}_{\mathrm{b}}$ belongs to the strongstrong combination.

\subsection{Cluster dependent brand association based on product network}

Transitiveness is the number of transmittable triples divided by the transitivity of potential transmittable triples. In social network analysis, transferability is a very important feature. Product $\mathrm{A}$ is connected to product $\mathrm{B}$, and product $\mathrm{B}$ is connected to product $\mathrm{C}$, and product $\mathrm{A}$ is connected to product $\mathrm{C}$. This triangular relationship indicates that the relationship is transferable (transitive).In the product network, this transitive relationship indicates that the relationships between product nodes are relatively tight. Co-brands built together by highly clustered product networks will have the ability to effectively control and utilize resources. Clustering can be understood in the product network as the degree to which the product will be a strategic relationship, that is, the degree of accumulation of consumer resources. 


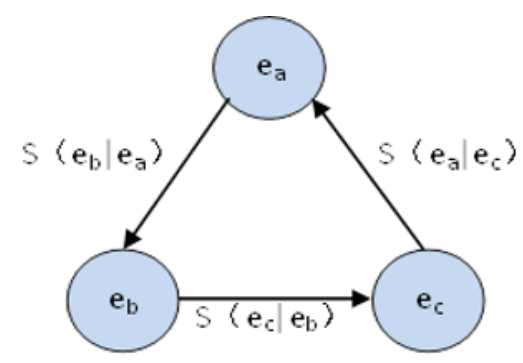

Fig. 3. Cluster-based brand association.

In the ternary brand association, the transformation of consumer resources is a closed-loop transformation that can prevent the loss of resources and increase the conversion rate of consumers among different products. Through the cluster analysis of social networks to analyze the network structure of geographical indication agricultural products, it is conducive to the construction of brand association of ternary transfer, that is, clusterbased brand association. The transformation of consumer resources is a cyclical process. The regional brands formed by the cluster-based brands can effectively control and utilize resources. In this paper, the resource sharing ability among geographical indication products, that is, the aggregation power of geographical indication brands, is studied through clustering. In the geographical indication agricultural product network, the landmark products that are combined by the cluster-dependent brand can usually gather regional resources to form the geographical integration of geographical indication brands and promote the development of the regional economy.

\section{Conclusions and Outlook}

The geographical indication agricultural product network of this paper is formed based on the consumer's independent purchasing behavior. Deep understanding of the structure of the geographical indication agricultural product network can guide the joint behavior of agricultural product brands. This study builds a joint mechanism of geographical indication agricultural product brands based on the product network formed by consumer purchasing behavior. Concluded as follow:

(1) A brand-based joint mechanism based on resource dependence. Based on the reciprocity research of social networks, this paper analyzes the brand joint behavior of products in the geographical indication agricultural product network from the perspective of resource acquisition and resource control. As a slowgrowing, resource-dependent agricultural product brand, it will tend to bring more consumer-converted product brands to brand alliance and obtain more resources. In addition to choosing strong alliances, the agricultural products brands entering the mature stage will also choose resource recipients to carry out brand alliances in order to improve their resource control capabilities, and enhance the resource control of the brand of this product.

(2) Brand-based joint mechanism based on cluster support. Based on the transitivity/clustering research of social networks, this paper explores the consumer transformation between ternary product brands. Brand alliances in a closed-loop state can prevent the loss of resources and increase the conversion rate of consumers between different products. For the regional economic development, through clustering research on the resource sharing ability between GI products, the brand-based joint mechanism relying on clusters can enhance the aggregation of GI brands and promote regional economic development.

This paper explores the mechanism of GI branding under different starting points through social network methods, which provides a new idea for regional brand building. At present, the research only proposes exploratory ideas, and the in-depth exploration of the complex evolution of product networks and brand joint mechanisms will be the next research direction.

\section{References}

1. Capaldo.A.Network structure and innovation: The leaver-aging of a dual network as a distinctive relational capability [J].Strategic Management Journal,2007,28(6):585-608.

2. Liu Qiuhong.Brand Network: A New Perspective of Brand Management [J].Science and Technology Progress and Countermeasures,2005,(6):76-83.

3. Guo Hongsheng,Zhou Xin,Eco-geographical indication of agricultural product brand relationship management [J].Enterprise Vitality 2007 (11): 19-21.

4. Cao Gaoming.Discussion on the New Ideas of Regional Brand Development_-Brand Alliance[J].Science and Technology Plaza,2012(11):168-171.

5. Xie Hongming,Wang Xianwei,Wu Zuo, Yu Wei.2008.Innovative research on clusters, networks and IJVs [J],Research Management,29(6): 23-29.

6. Xie Hongming,Ren Yanyan,Chen Ying,Cheng Cong,Cheng Xuanmei.2014.Research on the Relationship between Network Reciprocity and Enterprise Management Innovation-Based on the Perspective of Learning Ability and Member Aggregation[J].Scientific research management,(1): 90-97.

7. Maimon O,Rokach L.Data Mining and Knowledge Discovery Handbook Introduction to Supervised Methods[J].2005,10.1007/b107408(Chapter 8):149164.

8. Newman,M.E.J.2010.Networhs: An Introduction [M].Oxford University Press. 